\title{
ANALISIS POTENSI WILAYAH TANAH LONGSOR DI KAWASAN LERENG GUNUNG WILIS DENGAN MENGGUNAKAN DATA DEM TERRASAR-X
}

\author{
Lalu Muhamad Jaelani ${ }^{1}$, Rizha Fahlefi ${ }^{2}$ \\ ${ }^{1,2}$ Departemen Teknik Geomatika, FTSLK-ITS, Kampus ITS Sukolilo, Surabaya, 60111, Indonesia \\ e-mail: ${ }^{1}$ Imjaelani@geodesy.its.ac.id, ${ }^{2}$ fahlefirizha@gmail.com
}

\begin{abstract}
Abstrak
Tanah longsor seringkali terjadi ketika musim penghujan dengan tingkat curah hujan tinggi yang umumnya terjadi pada kelerengan tanah cukup curam. Air juga merupakan faktor penting yang dapat mempengaruhi terjadinya longsor. Pada bulan April 2017 lalu, terjadi peristiwa longsor di beberapa lokasi kawasan lereng gunung Wilis. Adanya peristiwa longsor tinggi dan terjadi dalam waktu bersamaan di lereng gunung Wilis, untuk itu perlu dilakukan penelitian potensi tanah longsor dengan menggunakan data DEM TERRASAR-X yang memiliki resolusi tinggi dalam menghasilkan data ketinggian tanah. Dengan menggabungkan faktor lain seperti data tutupan lahan, jenis geologi, dan jumlah curah hujan akan didapatkan informasi tingkat potensi tanah longsor di lereng gunung Wilis. Metode pengolahan dengan mempertimbangkan skor setiap kelas parameter dan pembobotan sebesar $20 \%$ tutupan lahan, $20 \%$ curah hujan, $30 \%$ jenis geologi, serta 30\% kelerengan tanah akan didapatkan informasi potensi longsor dengan rentang 0,8-1,375 dikategorikan rendah, 1,375-1,95 kategori menengah, 1,95-2,525 untuk kategori tinggi dan rentang 2,525-3,1 untuk kategori sangat tinggi. Potensi longsor akan dibandingkan dengan data rekam kejadian tanah longsor di lapangan dalam rentang waktu 2-5 tahun terakhir sebelum 2017. Hasil perbandingan sebagian besar menunjukkan adanya kesesuaian terkait wilayah yang berpotensi tinggi terhadap longsor dengan peristiwa yang terjadi di lapangan.
\end{abstract}

Kata kunci : Tanah Longsor, DEM TERRASAR-X, Potensi, Intensitas, Lereng

\begin{abstract}
Landslide is often occurrence when the rainy with high rainfall levels, were generally occurred on the steep slope. Water is also an important factor that can affect to the landslide. In April 2017, even occurred landslides on a few locations in the Mount Slope of Wilis. High landslide on the locations and almost incident at the same time in the Mount Slope of Wilis, because of that needs to be done the research to find the potential landslides using DEM TERRASAR-X data which has a high resolution on generating elevation data. Combining with any factors such as land cover, geology, and rainfall would be obtained information level of the potential landslides in the Mount Slope of Wilis. Processing method considering score every factors of the class and gave for weighting of $20 \%$ of land cover, $20 \%$ of rainfall, 30\% of geology, and 30\% of slope soil that would be obtained potential landslide information with the range 0.8-1.375 low category, 1.375-1.95 moderate category, 1.95-2.525 for high category, and 2.525-3.1 for very high category. Potential landslide would be compared with even landslide on the field in period of the time about 2-5 years before 2017. The results of the comparisons mostly show the potential area related to incidents in the research location.
\end{abstract}

Keywords : Landslide, DEM TERRASAR-X, Potential, Intensity, Slope 


\section{PENDAHULUAN}

Bencana alam merupakan salah satu fenomena alam yang bisa terjadi setiap saat, kapanpun, dan di tempat yang memiliki kelerengan, sehingga menimbulkan kerugian bagi masyarakat baik ditinjau dari segi material maupun non-material. Tanah longsor merupakan salah satu bencana alam yang dapat menimbulkan kerugian akibat pergerakan blok tanah pada permukaan bumi yang memiliki tingkat kemiringan yang cukup curam (Nugroho, Sukojo, \& Sari 2009).

Air merupakan salah satu penyebab utama terjadinya tanah longsor dikarenakan bertambahnya beban tanah pada lapisan kedap air yang memicu terjadinya pergerakan tanah pada bidang gelincir akibat terjadinya pelapukan (PVMBG 2005). Berdasarkan data geologi, Gunung Wilis tergolong gunung api pasif dengan ditemukannya batuan lapuk di area gunun setebal lebih dari 20 meter (Fitria 2016).

Pemetaan zona tanah longsor dapat dilakukan dengan berbagai parameter dan metode yang berbeda-beda dimana setiap metode yang digunakan memiliki pembobotan masing-masing. Salah satu metode yakni analisis zona rawan tanah longsor dengan menggunakan data satelit dengan metode pembobotan Weighted Linear Combination. Selanjutnya mitigasi bencana ini dibedakan berdasarkan tingkatan risiko yaitu risiko rendah, sedang, dan tinggi. Selain itu, terdapat metode pengolahan dengan mempertimbangkan beberapa parameter diantaranya citra satelit resolusi menengah, DEM, peta geologi, dan curah hujan. Hanya saja penelitian yang pernah dilakukan tersebut terbatas di lereng gunung Wilis daerah Ponorogo saja yang dilakukan pemetaan zona wilayah tanah longsor.

Untuk itu dalam penelitian ini dilakukan pengolahan data dalam pemetaan zona tanah longsor dengan menggunakan citra satelit, DEM, peta geologi, dan curah hujan untuk seluruh wilayah lereng gunung Wilis yang terbagi kedalam beberapa Kabupaten agar secara keseluruhan terdapat pemetaan zonasi tanah longsor. Beberapa parameter tersebut dilakukan skoring data dengan pembagian kelas dan nilai untuk klasifikasi, yang kemudian akan ditampalkan untuk mengetahui wilayah yang memiliki potensi dan berisiko terjadi tanah longsor.

Saat ini perlu adanya tindakan untuk melakukan pencegahan lebih dini agar masyarakat yang berada di sekitar area rawan bencana, area resiko bencana dapat melakukan pencegahan dengan memelihara lingkungan sekitar dan dapat melakukan tindakan jika terjadi hal yang tidak diinginkan. Untuk itu, dalam penelitian ini akan dilakukan pemetaan zona longsor di lereng gunung Wilis sebagai upaya dasar untuk melakukan pencegahan dini lebih lanjut.

\section{METODE}

\section{Lokasi Penelitian}

Secara administrative, gunung Wilis berada di perbatasan enam kabupaten diantaranya Kabupaten Madiun, Nganjuk, Kediri, Tulungagung, Trenggalek, dan Ponorogo yang berada pada koordinat $07^{\circ} 46^{\prime} 27^{\prime \prime}$ LS sampai $07^{\circ} 57^{\prime} 6^{\prime \prime}$ LS dan $111^{\circ} 38^{\prime} 45^{\prime \prime}$ BT sampai $111^{\circ} 40^{\prime} 40^{\prime \prime}$ BT, dengan puncak ketinggian $2.563 \mathrm{mdpl}$ (meter diatas permukaan laut).

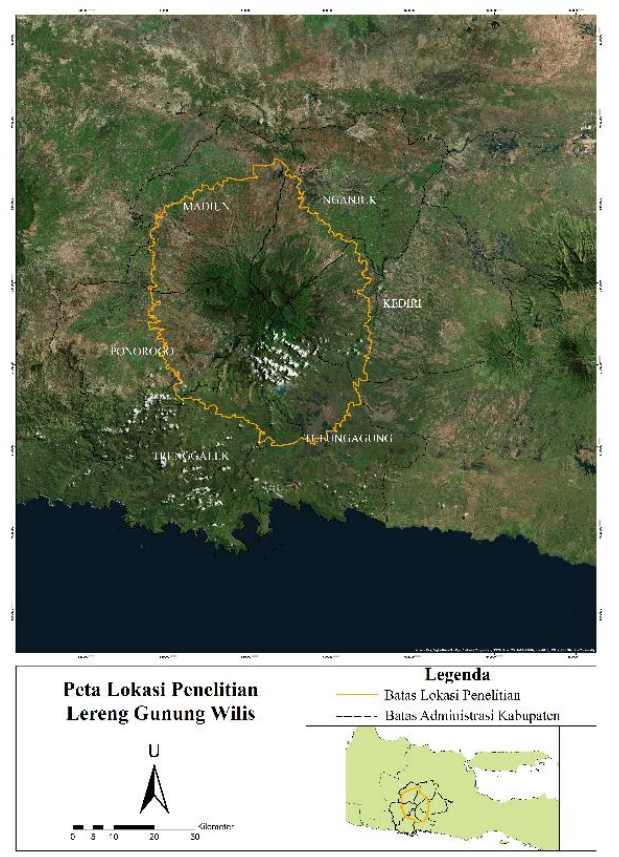

Gambar 1. Lokasi Penelitian Lereng Gunung Wilis

\section{Data}

Adapun data yang digunakan dalam penelitian tugas akhir ini adalah sebagai berikut :

a. Data Citra Satelit Resolusi Menengah, yaitu citra Sentinel 2-A dengan resolusi spasial 10 meter

b. Data Citra Satelit RADAR 
- Citra TerraSARX dengan ukuran grid 10 meter (6 scene)

- Interval kontur 5 meter

c. Peta Geologi lembar Madiun, Ponorogo, Tulungagung, Pacitan, Blitar, Kediri, dan Bojonegoro skala 1:100.000

d. Data curah hujan bulanan Maret 2017 dan Juli 2016 dari BMKG Jawa Timur pada area Kabupaten Madiun, Nganjuk, Kediri, Tulungagung, Trenggalek, dan Ponorogo

e. Peta Rupa Bumi Indonesia berupa data batas administrasi untuk batas Kabupaten dan Kecamatan wilayah penelitian.

f. Data rekam kejadian longsor tahun rentang tahun 2013 - 2017 dari Badan Penanggulangan Bencana Daerah Kabupaten Madiun, Nganjuk, Kediri, Tulungagung, Trenggalek, dan Ponorogo.

\section{Peralatan}

Adapun data yang digunakan dalam penelitian tugas akhir ini adalah sebagai berikut :
a. Microsoft Office
b. Perangkat lunak pengolah data citra satelit, DEM, peta geologi dan curah hujan.
c. GPS Handheld

\section{Tahapan Penelitian}

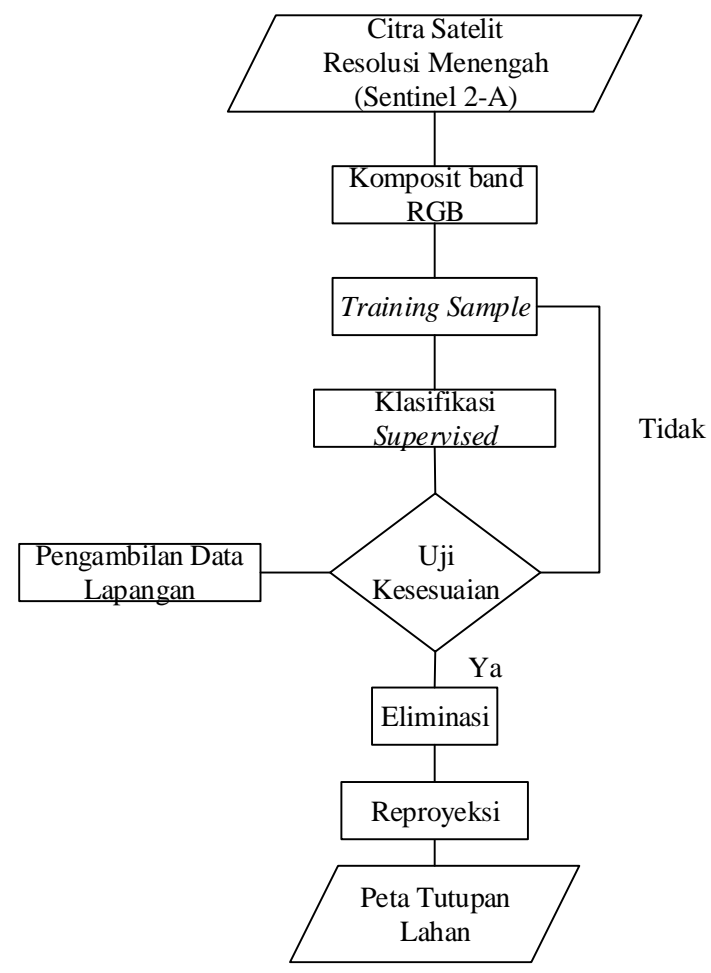

Gambar 2. Diagram Alir Tutupan Lahan

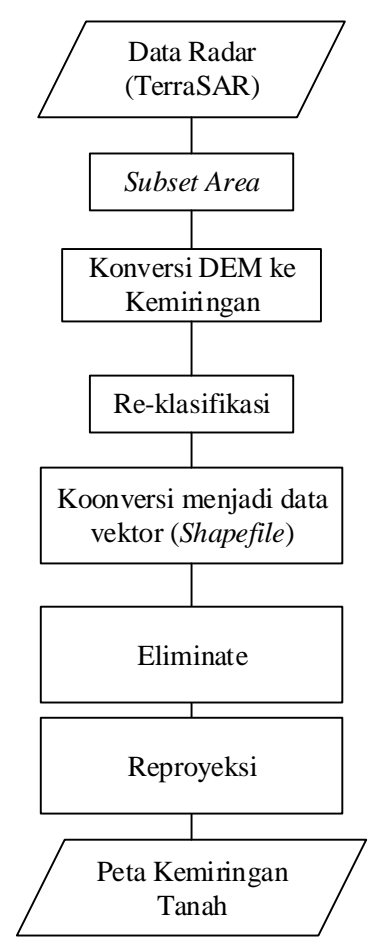

Gambar 3. Diagram Alir Kemiringan Tanah

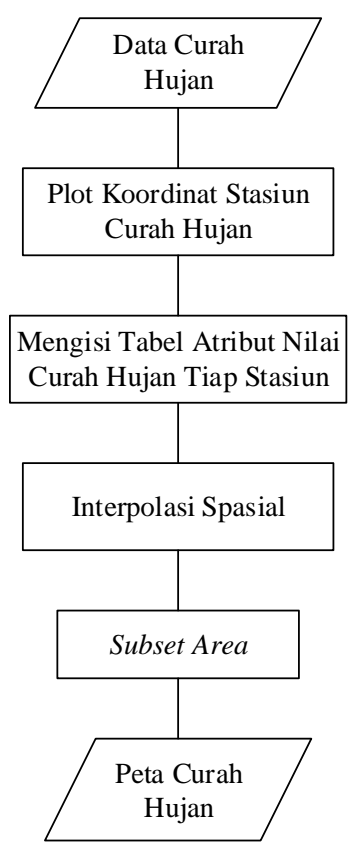

Gambar 4. Diagram Alir Curah Hujan

a. Pengolahan Data

Keempat proses data diuraikan pada beberapa diagram diatas diantaranta adalah data tutupan lahan yang didapat dari citra sentinel$2 \mathrm{~A}$, kemiringan tanah dari data DEM TERRASAR-X, peta geologi, serta data curah hujan. 
Data geologi diperoleh melalui proses digitasi dari peta geologi kemudian diberikan informasi atribut untuk menggambarkan data spasial yang didapatkan. Sedangkan data curah hujan berupa plot koordinat stasiun pemantau yang dilakukan proses interpolasi spasial dengan membagi kedalam beberapa kelas nilai curah hujan yang sesuai. Keempat data tersebut disubset sesuai dengan lokasi penelitian dimana perlu disesuaikan sistem koordinat yang sama yaitu UTM zona 49S.

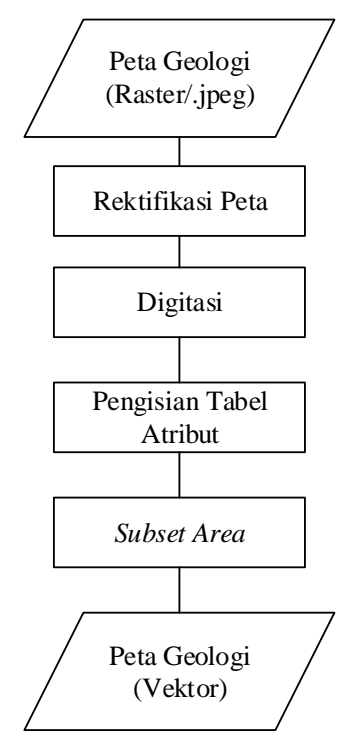

b. Penggabungan Data

Proses ini dilakukan untuk menggabungkan data-data yang dihasilkan. Data ini akan saling melakukan iris poligon dimana setiap poligon baru yang terbentuk memiliki ke empat informasi dari setiap parameter yang digunakan. Proses penggabungan dilakukan melalui dua tahap yakni tahap yang pertama menggabungkan data jenis tanah dengan data kelerengan tanah, kemudian menggabungkan data tutupan lahan dengan data curah hujan. Setelah menjadi dua data baru hasil overlay pertama, kemudian kedua data overlay tersebut digabungkan menjadi satu data.

c. Pembobotan dan Analisis

Melakukan skoring atau pembobotan dengan klasifikasi nilai atau kelas tertentu untuk membedakan tingkat dari yang paling rendah ke tingkat paling tinggi dari setiap parameter seperti nilai volume curah hujan, nilai besar kemiringan tanah, jenis tanah, dan lain sebagainya dan kemudian dilakukan interpretasi serta analisis untuk membagi data kedalam kategori, kelas atau berdasarkan skoring yang telah ditentukan.

Gambar 5. Diagram Alir Jenis Geologi

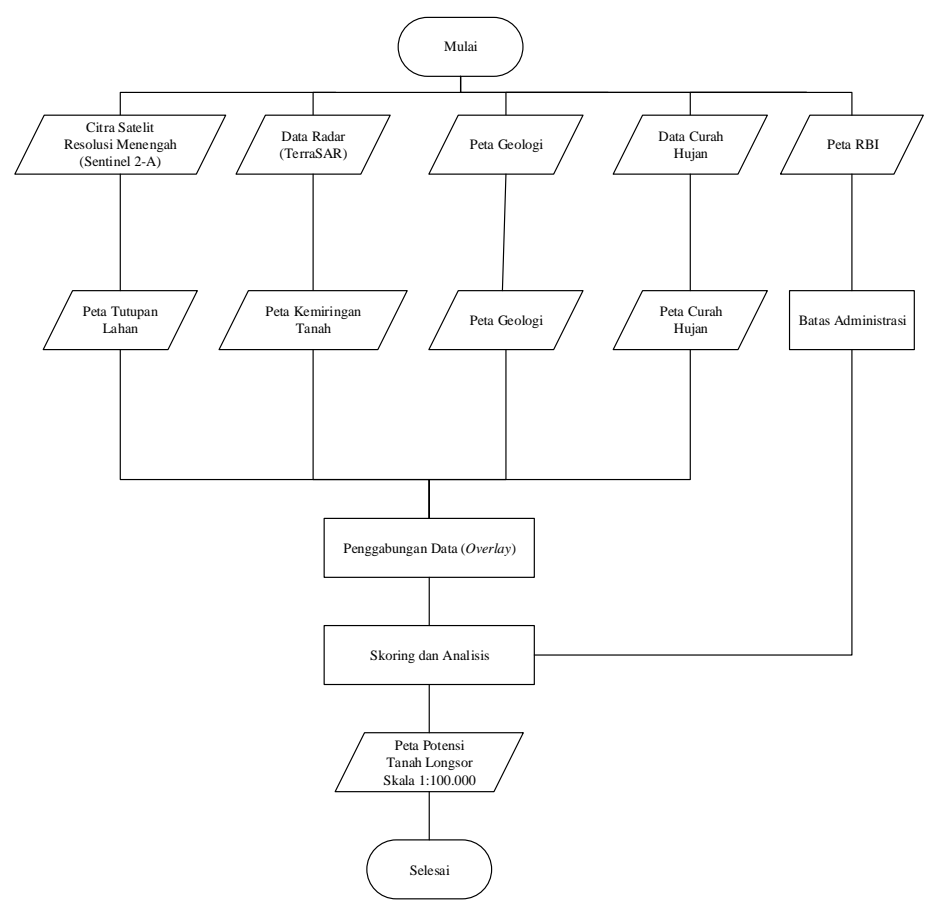

Gambar 6. Diagram Alir Metodologi Secara Umum 
d. Pembobotan Akhir

Pembobotan akhir ini merupakan akumulasi dari persentase dikalikan bobot tiap parameter kemudian menghasilkan suatu nilai baru dimana nilai tersebut nantinya diklasifikasi berdasarkan tingkat kerentanan atau berpotensi terjadi tanah longsor.

e. Validasi

Kemudian dilakukan validasi data dengan laporan bencana longsor yang terjadi di lokasi tersebut selama tahun 2017. Validasi juga akan dilakukan dengan membandingkan laporan kejadian tanah longsor beberapa tahun sebelum tahun 2017.

f. Peta Potensi Longsor

Setelah semua dianggap sudah sesuai baik dari data dan validasi, maka data dapat ditampilkan menjadi peta rawan dan resiko bencana longsor lereng gunung Wilis skala 1:100.000.

\section{HASIL DAN PEMBAHASAN}

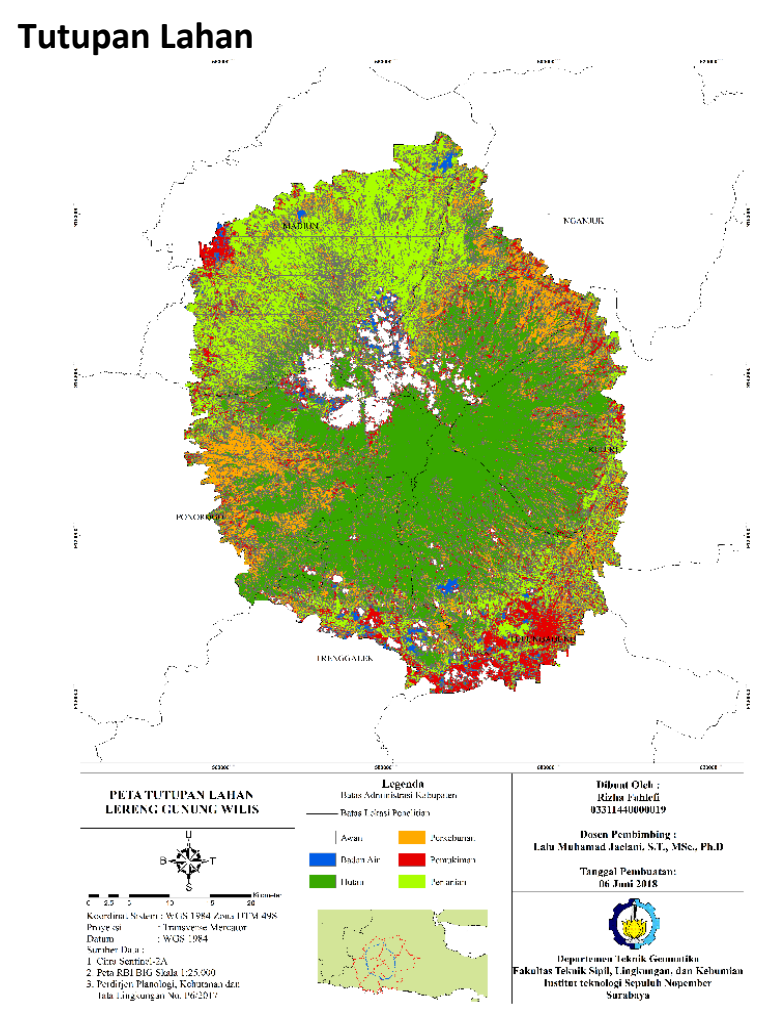

Gambar 7. Peta Tutupan Lahan Lereng Gunung Wilis

Data tutupan lahan didapatkan dari citra sentinel2A melalui pengolahan menggunakan salah satu perangkat lunak. Data citra ditampilkan dengan visualisasi RGB (tampak berwarna) dengan kanal 4,3 , dan 2 dari sentinel-2A. Citra sentinel-2A telah dilakukan proses koreksi geometrik sebanyak 30 titik sampel pada lokasi penelitian agar kondisi pada citra yang akan dilakukan proses pengolahan data telah sesuai dengan kondisi di lapangan.

Untuk mengetahui tingkat akurasi atau ketelitian yang dihasilkan proses klasifikasi tersebut yaitu dengan menggunakan uji akurasi matriks konfusi. Matriks konfusi ditunjukkan pada Tabel 1.

Tabel 1. Matriks Konfusi Tutupan Lahan

\begin{tabular}{|c|c|c|c|c|c|c|c|c|}
\hline \multirow{2}{*}{$\begin{array}{c}\text { Data } \\
\text { Klasifik } \\
\text { asi }\end{array}$} & \multicolumn{6}{|c|}{ Data Referensi } & \multirow{2}{*}{$\begin{array}{l}\text { Total } \\
\text { Baris }\end{array}$} & \multirow{2}{*}{$\begin{array}{c}\text { User's } \\
\text { Accuracy } \\
\text { (\%) }\end{array}$} \\
\hline & $\begin{array}{c}\text { Perkeb } \\
\text { unan }\end{array}$ & $\begin{array}{c}\text { Perta } \\
\text { nian }\end{array}$ & Hutan & $\begin{array}{l}\text { Pemu } \\
\text { kiman }\end{array}$ & $\begin{array}{l}\text { Badan } \\
\text { Air }\end{array}$ & Awan & & \\
\hline $\begin{array}{l}\text { Perkeb } \\
\text { unan }\end{array}$ & 30 & 7 & 2 & 0 & 0 & 0 & 39 & 77 \\
\hline $\begin{array}{l}\text { Pertan } \\
\text { ian }\end{array}$ & 8 & 31 & 2 & 0 & 1 & 0 & 42 & 74 \\
\hline Hutan & 1 & 5 & 37 & 0 & 0 & 0 & 43 & 86 \\
\hline $\begin{array}{l}\text { Pemuk } \\
\text { iman }\end{array}$ & 1 & 2 & 1 & 77 & 0 & 0 & 81 & 95 \\
\hline $\begin{array}{l}\text { Badan } \\
\text { Air }\end{array}$ & 2 & 8 & 2 & 2 & 21 & 0 & 35 & 60 \\
\hline Awan & 0 & 0 & 0 & 0 & 0 & 30 & 30 & 100 \\
\hline $\begin{array}{c}\text { Total } \\
\text { Kolom } \\
\end{array}$ & 42 & 44 & 53 & 79 & 22 & 30 & 270 & \\
\hline $\begin{array}{c}\text { Kappa } \\
(k)=\end{array}$ & & \multicolumn{7}{|c|}{$79,9 \%=0,799$} \\
\hline $\begin{array}{c}\text { Overal } \\
I \\
\text { accura } \\
c y=\end{array}$ & & \multicolumn{7}{|c|}{$83,7 \%=0,837$} \\
\hline
\end{tabular}

Dapat dilihat pada Tabel 1 tersebut bahwa nilai akurasi overall klasifikasi adalah 83,7\%, sedangkan untuk koefisien kappa sebesar 0,799 dari jumlah sampel yang diambil sekitar 240 titik.

\section{Kemiringan Tanah}

Data kemiringan data dihasilkan melalui proses pengolahan dari DEM TERRASAR-X dimana data tersebut memiliki nilai ketinggian atau elevasi dari permukaan daerah yang terekam. Data dari DEM diubah menjadi kemiringan dengan penentuan berdasarkan persentase kemiringan tanah yang dibagi kedalam beberapa kelas pada nilai DEM tersebut.

Pemberian nilai kelas atau skoring berdasarkan acuan rentang nilai yang terbagi kedalam empat kelas. Sehingga perlu adanya pengklasifikasian ulang nilai kemiringan sesuai rentang nilai dan kelas yang dibutuhkan. Rentang nilai tersebut diantaranya $0 \%-8 \%$ bersifat datar dan landai, $8-25 \%$ bersifat agak curam, 25\%-45\% bersifat curam, dan kemiringan diatas $45 \%$ bersifat sangat curam. 


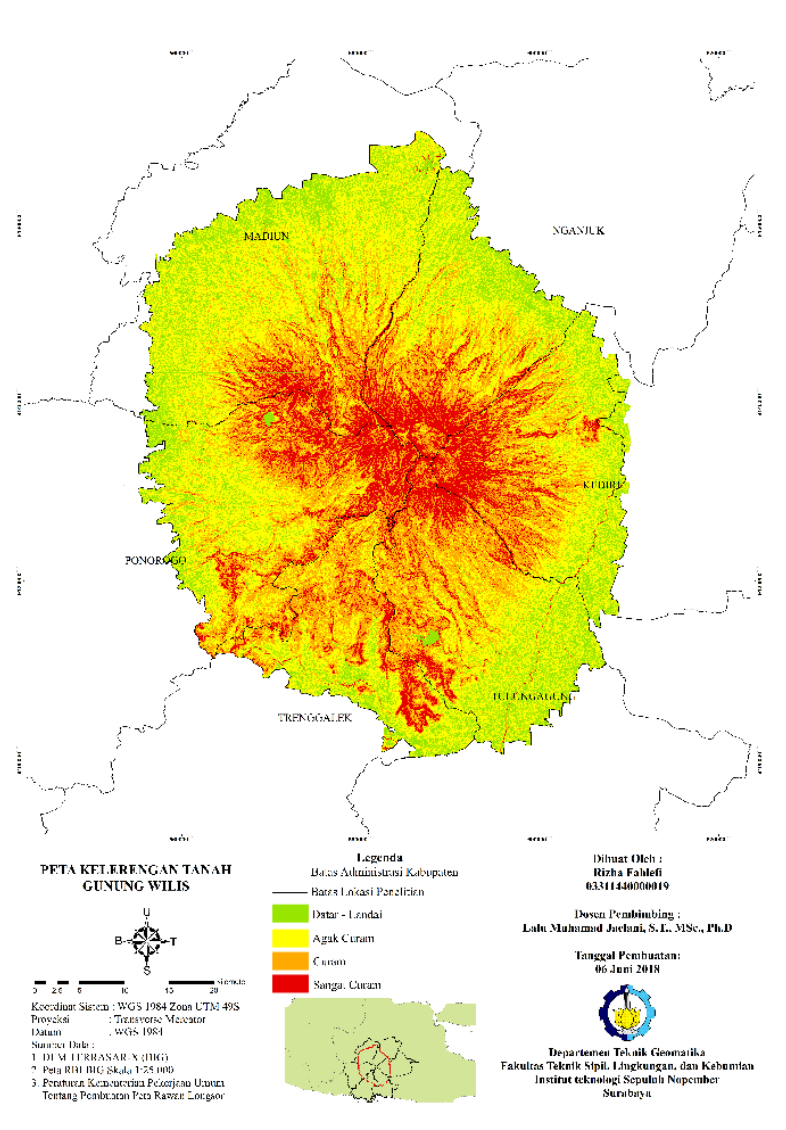

Gambar 8. Peta Kelerengan Tanah

\section{Curah Hujan}

Data curah hujan berupa titik-titik stasiun yang berisikan informasi besar nilai yang didapatkan dari tiap stasiun pemantau. Stasiun yang digunakan merupakan persebaran dari stasiun pemantau curah hujan di wilayah lokasi penelitian atau lebih tepatnya enam kabupaten lingkar lereng gunung Wilis.

Data curah hujan diproses menggunakan metode interpolasi Inverse Distance Weighted (IDW). Metode IDW mempertimbangkan interpolasi nilai berdasarkan kebalikan jarak antar titik. Semakin rapat titik maka hasil interpolasi antar titik tersebut semakin baik. Hasil interpolasi berupa data raster yang perlu diubah menjadi data vektor kemudian dipotong (subset) berdasarkan lokasi penelitian yaitu lereng gunung Wilis.

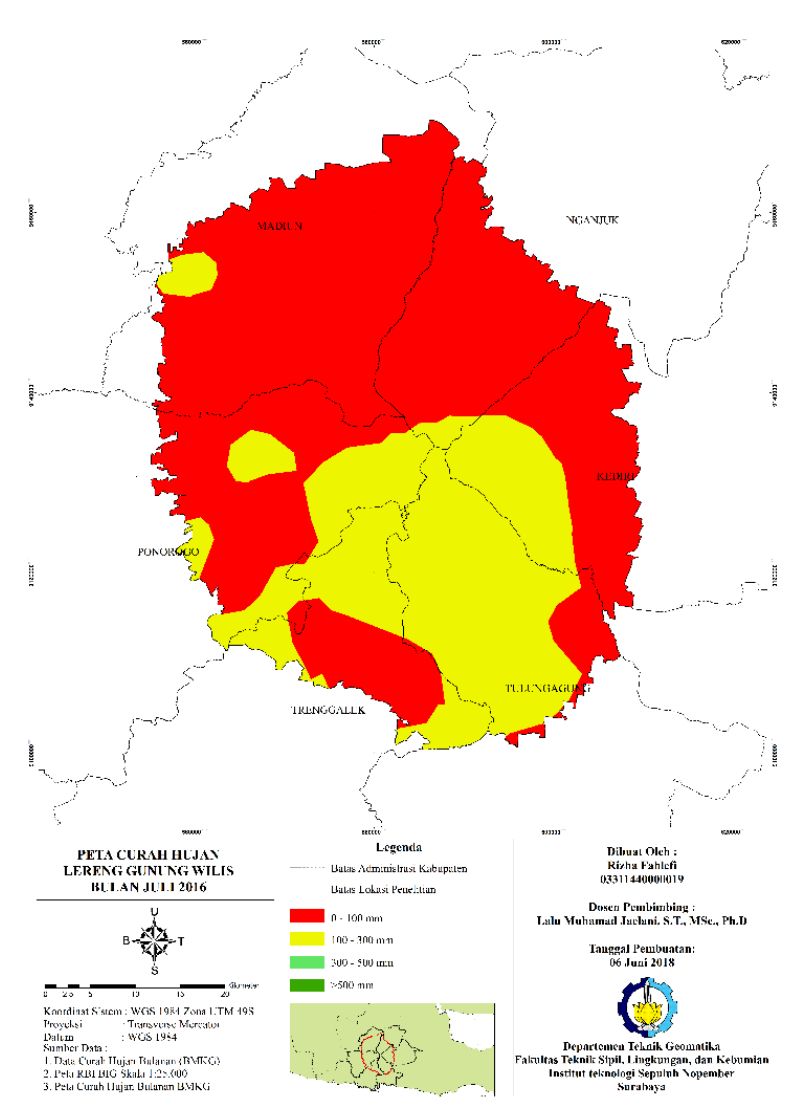

Gambar 9. Peta Curah Hujan Bulan Juli 2016

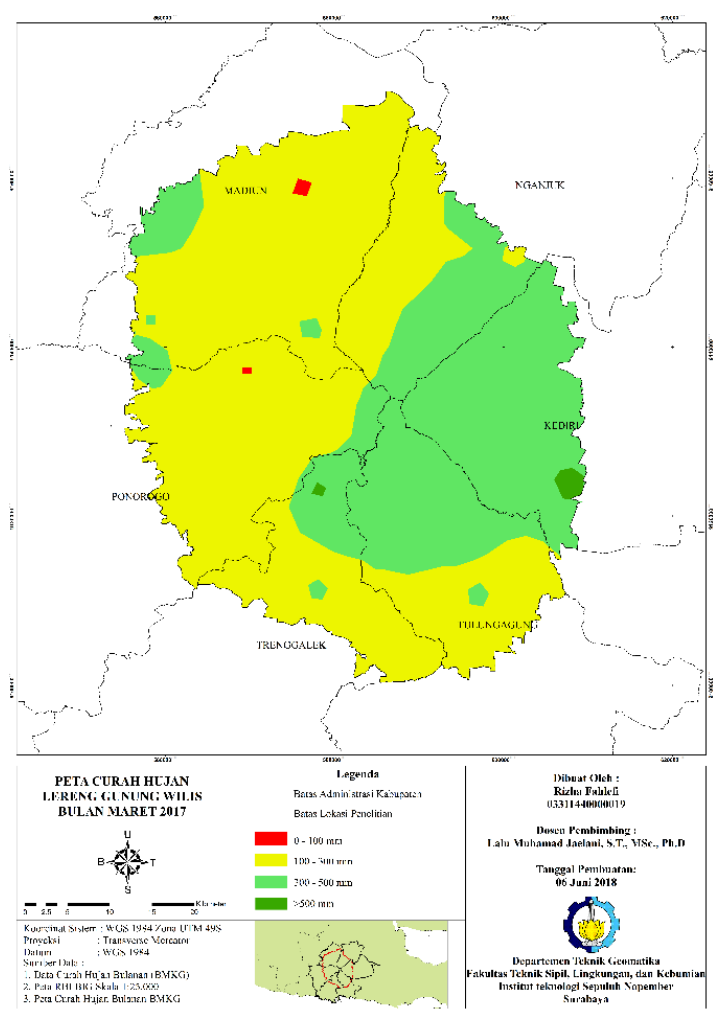

Gambar 10. Peta Curah Hujan Bulan Maret 2017 


\section{Peta Geologi}

Data jenis tanah merupakan salah satu faktor yang memiliki persentase bobot cukup besar pada penelitian ini yaitu 30\%. Hal ini dikarenakan karakteristik lapisan jenis tanah yang berbeda mempengaruhi tingkat kekuatan hingga kelapukan lapisan tanah. Jenis tanah yang berada pada gunung Wilis dapat dikelompokkan kedalam beberapa jenis diantaranya batuan terobosan, aluviall, formasi, dan morfonit/morfoset.

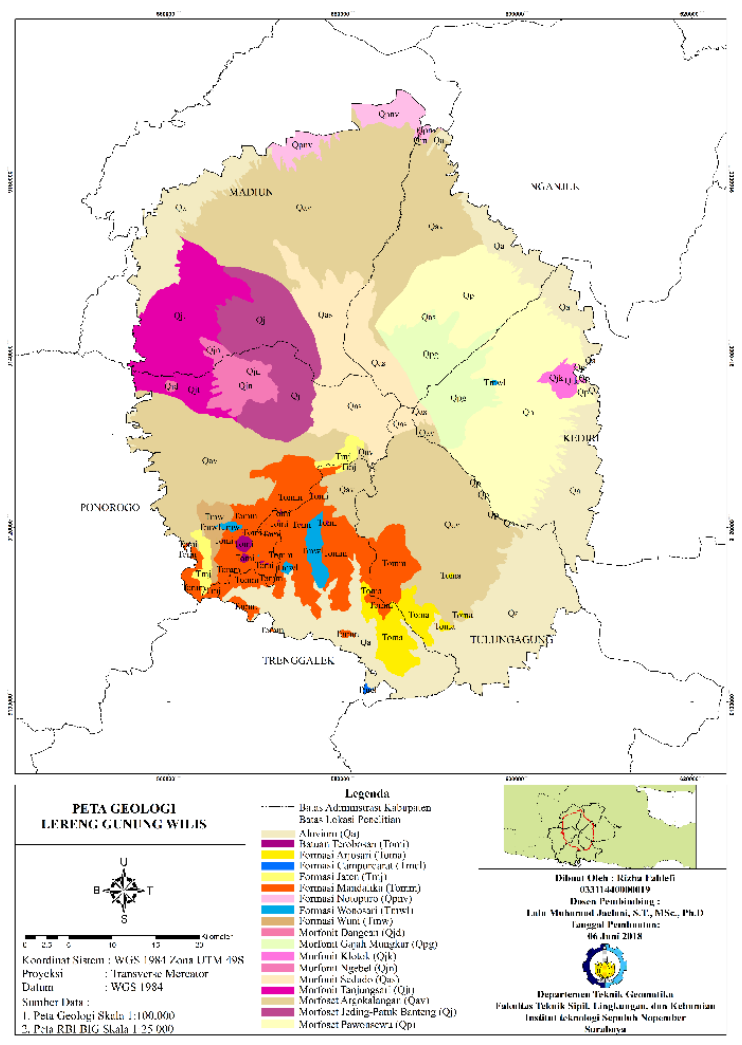

Gambar 11. Peta Geologi

\section{Zonasi Potensi Tanah Longsor}

Skoring dan pembobotan parameter dilakukan setelah menggabungkan keempat data melalui overlay sederhana. Tutupan lahan memiliki bobot sebesar 20\%, kelerengan tanah sebesar 30\%, curah hujan sebesar $20 \%$, dan jenis tanah sebesar $30 \%$. Setiap skor kelas data dikalikan dengan bobot data menghasilkan nilai yang kemudian dijumlahkan total nilai dari keempat data tersebut. Sehingga total akhir nilai yang didapatkan digunakan untuk menentukan tingkat potensi tanah longsor di wilayah lereng gunung Wilis.

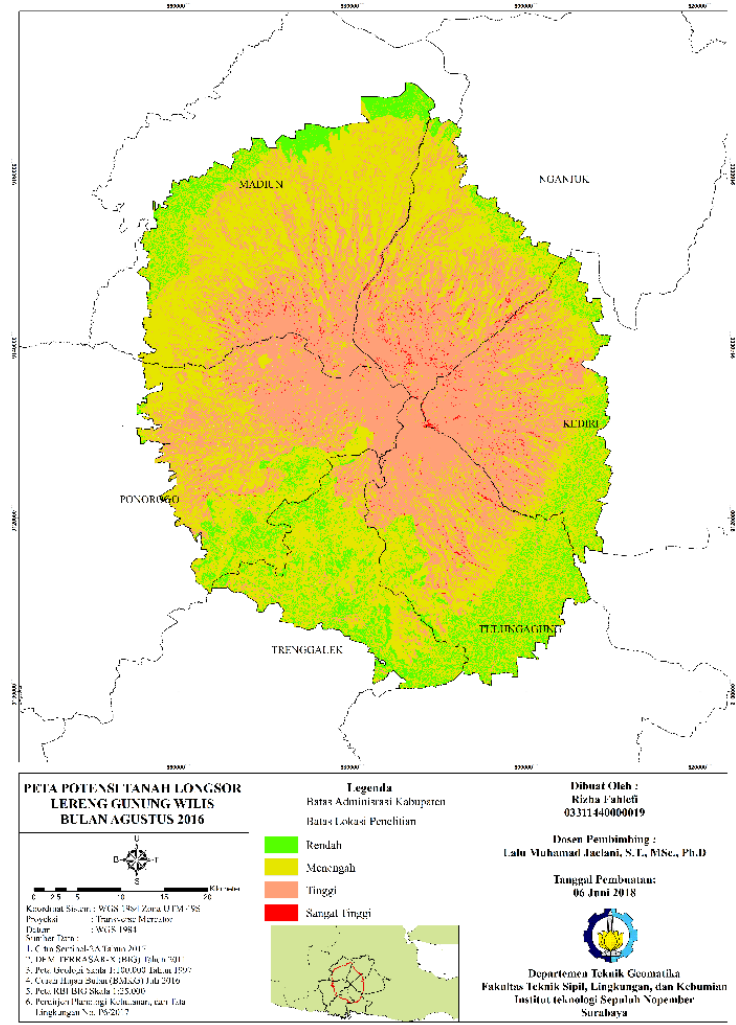

Gambar 12. Peta Potensi Tanah Longsor Bulan Agustus 2016

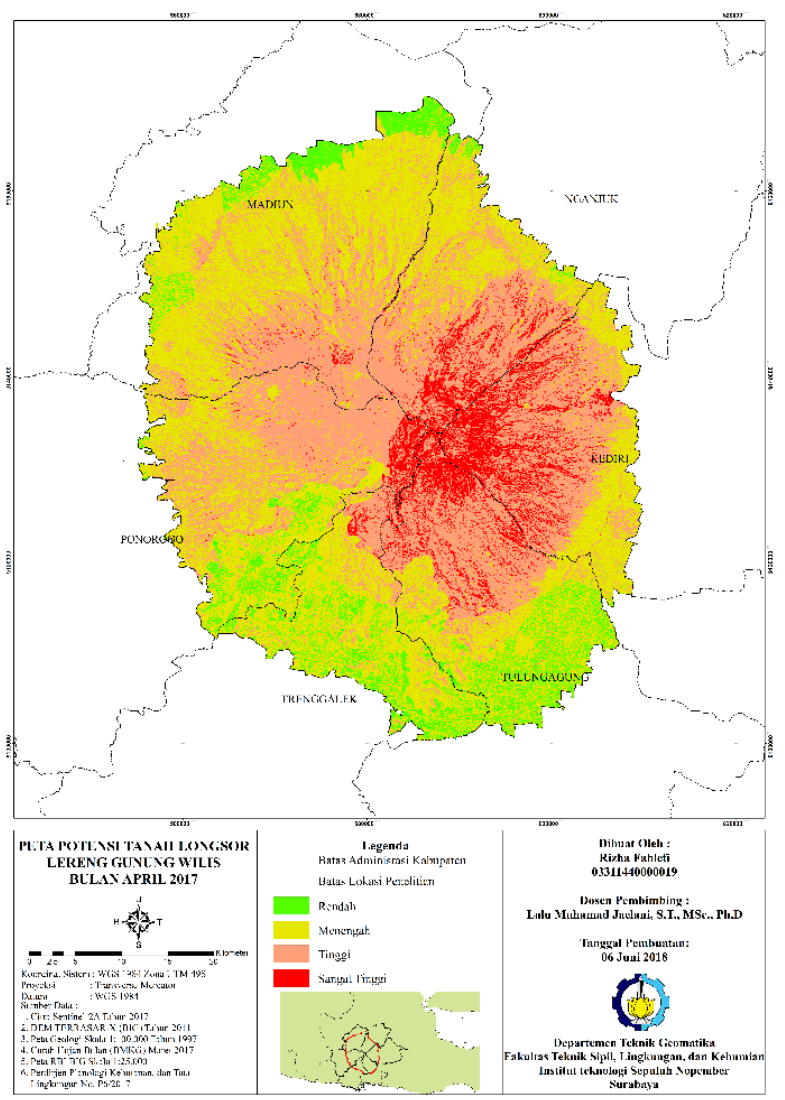

Gambar 12. Peta Potensi Tanah Longsor Bulan April 2017 
Gambar 12. menunjukkan lokasi yang memiliki tingkat potensi sangat tinggi dengan luas $212,065 \mathrm{~km}^{2}$. Wilayah dengan potensi tinggi meningkat dari luas 1044,3 $\mathrm{km}^{2}$ (Agustus 2016) menjadi $1275.785 \mathrm{~km}^{2}$ (April 2017). Wilayah dengan potensi menengah menurun dari $1400,639 \mathrm{~km}^{2}$ menjadi $1249,332 \mathrm{~km}^{2}$. Sedangkan wilayah yang berpotensi rendah terhadap longsor juga menurun pada musim penghujan dengan luas area $295 \mathrm{~km}^{2}$ menjadi $214.158 \mathrm{~km}^{2}$. Hal ini diakibatkan perbedaan besar curah hujan yang cukup signifikan di kedua waktu yang berbeda.

\section{Analisis}

Peta potensi tanah longsor diproses dengan melakukan overlay terhadap empat data yaitu tutupan lahan, data geologi, curah hujan dan kelerengan tanah. Pada keempat data tersebut diberikan skor pada masing-masing kelas, semakin tinggi skornya maka daerah tersebut berpotensi terjadi tanah longsor, dan makin besar pembobotan dari setiap data maka data tersebut memiliki pengaruh yang lebih besar terhadap data lainnya.

Ditunjukkan bahwa parameter yang lebih dominan terhadap penentuan potensi tanah longsor adalah parameter kelerengan tanah dan jenis geologi dengan bobot yang sama yaitu $30 \%$. $\mathrm{Hal}$ ini dikarenakan tingkat kelerengan tanah yang sangat curam mempengaruhi potensi terjadinya longsor ditambah dengan tingkat kekuatan lapisan geologi yang mempengaruhi kelapukan tanah di lokasi tersebut (Khoiri, Jaelani, \& Widodo 2014).

Secara umum perbedaan perubahan tingkat potensi longsor suatu wilayah antara Agustus 2016 dan April 2017 cukup signifikan. Masing-masing daerah Kabupaten lokasi penelitian menunjukkan perubahan luas potensi yang cukup tinggi.

Wilayah dengan potensi sangat tinggi lebih banyak terjadi di Kabupaten Kediri, Nganjuk, Tulungagung, dan Ponorogo. Hal ini disebabkan jenis geologi pada wilayah tersebut yaitu Morfonit/Morfoset dimana jenis ini memiliki tingkat ketahanan yang lemah. Selain itu wilayah tersebut berada pada kelerengan yang curam dengan intensitas curah hujan yang tinggi. Sedangkan di Kabupaten Madiun dan Ponorogo terdapat wilayah yang tertutup awan mengakibatkan pengurangan skor pada pembobotan akhir dalam penentuan tingkat potensi terjadinya longsor. Sehingga tidak didapatkan hasil yang sesuai dengan kondisi nyata karena tutupan lahan diidentifikasi sebagai awan.

Adapun lokasi dengan potensi menengah dan rendah relatif terjadi pada kelerengan yang datar atau landai. Selain itu tingkat intensitas curah hujan relatif lebih rendah. Sedangkan untuk jenis geologi pada wilayah tersebut disusun dari jenis formasi dan alluvial dimana kedua jenis ini memiliki ketahanan yang lebih kuat dibanding jenis Morfonit/Morfoset.

\section{KESIMPULAN}

Berdasarkan hasil penelitian mengenai kerentanan tanah longsor daerah lereng gunung Wilis maka didapatkan kesimpulan sebagai berikut:

a. Penelitian ini memerlukan empat data utama yaitu tutupan lahan, kelerengan tanah, jenis tanah, dan curah hujan. Dari data tutupan lahan didapatkan tingkat akurasi klasifikasi yang dihasilkan sebesar 0,799 (nilai kappa) atau overall accuracy sebesar $83,7 \%$.

b. Keempat data kemudian digabungkan dengan bobot tiap data mulai dari tutupan lahan sebesar $20 \%$, kelerengan tanah sebesar $30 \%$, jenis geologi sebesar $30 \%$, dan sisanya $20 \%$ untuk curah hujan bulanan. Data kelerengan tanah dan jenis geologi merupakan data yang paling dominan disbanding keempat data yang digunakan dengan bobot yang sama sebesar $30 \%$.

c. Wilayah lereng gunung Wilis dibagi kedalam empat tingkat potensi longsor diantaranya rendah, menengah, tinggi, dan sangat tinggi. Wilayah lebih dominan memiliki tingkat potensi tinggi di setiap wilayah Kabupaten. Wilayah dengan tingkat sangat tinggi banyak ditemui pada wilayah Kabupaten Kediri. Tingkat potensi ini dominan terjadi pada wilayah puncak gunung Wilis. Wilayah dengan tingkat potensi menengah berada pada area kaki gunung Wilis atau wilayah terluar dari lereng. Sedangkan hanya terdapat sedikit wilayah yang berada pada tingkat potensi rendah.

\section{UCAPAN TERIMA KASIH}

Penulis R. F. mengucapkan terima kasih kepada Pusat Studi Kebumian, Bencana, dan Perubahan Iklim yang memberikan fasilitas dalam melakukakn penelitian ini. Serta dukungan dan 
bantuan dari rekan-rekan mahasiswa Teknik Geomatika ITS.

\section{DAFTAR PUSTAKA}

Fitria, L. M. (2016). Analisa Kerentanan Bencana Longsor di Lereng Gunung Wilis Kabupaten Nganjuk, 1(1), 76-83.

Khoiri, M., Jaelani, L. M., \& Widodo, A. (2014). Risk Assessment Methodologies for Landslides in East Java, (Pvmbg 2005), 1-10.

Nugroho, J. A., Sukojo, B. M., \& Sari, I. L. (2009). Pemetaan Daerah Rawan Longsor dengan Penginderaan Jauh dan Sistem Informasi Geografis (Studi Kasus Hutan Lindung Kabupaten Mojokerto), 79-94.

PVMBG. (2005). Pengenalan Gerakan Tanah. Esdm. Retrieved from https://www.esdm.go.id/assets/ media/content/Pengenalan_Gerakan_Tanah.pdf 